carcinogens. Hueper was threatened and eventually fired over his investigations of worker exposure at the chemical company DuPont. At the US National Cancer Institute (NCI), Hueper pursued the connection between environment and cancer, before meeting industrial resistance. Drawing on Hueper's unpublished autobiography, Davis relates that industrial firms were "given extraordinary access to his papers prior to their being submitted for publication when he worked at NCI". Permission to publish was denied, and Hueper was directed to confine himself to animal studies.

Pessimistic about industry voluntarily mending its carcinogenic abuses or government forcing a cleanup, Davis proposes an intriguing remedy. The creation of a Truth and Reconciliation Commission (TRC), à la post-apartheid South Africa, would, she reck-

\title{
Promoting capitalism over Kyoto
}

\author{
Break Through: From the Death of \\ Environmentalism to the Politics of \\ Possibility \\ by Michael Shellenberger and Ted \\ Nordhaus \\ Houghton Mifflin: 2007. 256 pp. \$25
}

\section{Jonathon Porritt}

In 2005, Ted Nordhaus and Michael Shellenberger caused a furore among environmentalists when they published an article entitled 'The Death of Environmentalism' in the online magazine Grist. It combined penetrating insights into the inadequacies of contemporary environmental thinking with a robust, upbeat assessment of the opportunity to transform the global economy. At the time, it was exactly what was needed. But in elaborating their original thesis into a densely argued book, the self-styled 'bad boys of environmentalism' have largely lost the plot.

Their analysis of the historical relationship between affluence, economic security, personal identity and 'the American dream' is illuminating, particularly perhaps for European readers. Some of the early chapters assert a creative world view - on how best to deal with the rainforests in Brazil, for instance, or on the contrast between faith communities and the environmental movement. And their sustained, if repetitive, critique of conventional environmental thinking is still apposite. Many environmentalists are indeed too misanthropic, too focused on technocratic and regulatory solutions, and far too apocalyptic for their own good, let alone the good of the environment.

But Nordhaus and Shellenberger did all that three years ago. In Break Through, they overegg the pudding with grotesque exaggerations and generalizations, and with such a startling lack of generosity as to make one question their true ons, encourage industrial executives to confess to their environmental delinquencies: "The files of many large multinational businesses could easily tell us about many more health risks associated with workplace exposures of the past." Under a TRC regime, she suggests, "grace and forgiveness become the grounds for renewal and restoration".

Davis's inventory of long-standing corporate and government tolerance of known carcinogenic exposures is faultless. Her failure to acknowledge that in important respects the tide is turning detracts from the credibility of her work. Her call for a TRC is a strikingly imaginative gambit. Given the power and mood of corporate America, file it under 'fantasy'.

Daniel S. Greenberg, a journalist in Washington, is author of Science for Sale: The Perils, Rewards, and Delusions of Campus Capitalism. motives. For instance, they would have readers believe that they alone are advancing an investment-led approach to climate change (rather than the limits-based regulations embodied in the Kyoto Protocol). Not a mention of Natural Capitalism, the radiantly upbeat book by Paul Hawken, Amory Lovins and L. Hunter Lovins, or of the 30-years-plus of inspired, investmentdriven technology developments promoted by the Rocky Mountain Institute and Amory Lovins. Similarly, it would have been proper to commend the sophisticated global Marshall plan that Al Gore outlined in his 1992 book Earth in the Balance and to highlight the failure of Gore's documentary film An Inconvenient Truth to talk solutions.

The main disappointment is that Break Through does not produce any coherent new environmental agenda. There are a few references to the Apollo Project on clean energy, an excellent US initiative led by Nordhaus and Shellenberger, which unfortunately failed to gain political traction. Much more time is spent demolishing the environmental justice movement and discussing the inadequacies of 'not in my back yard' politicians than in spelling out how the environmental dream might actually become reality.

Also galling is the almost limitless flow of optimistic, unsubstantiated assertions about the benefits of a positive mindset. The authors urge environmentalists, instead of being so anti-growth, to proselytize that "things need to get a lot better economically before they can get better environmentally". I happen to agree with this view in terms of emerging countries such as China and India, let alone some of today's poorest nations, but Nordhaus and Shellenberger seem to position themselves outside the critical debate about the kind of economic growth required.

The political naïveté can be as painful as the spurious optimism. The damage done by seven years of the Bush administration is barely referenced. Capitalism is simply assumed to be a good thing, without any deeper analysis. Crude either/or dichotomies rule. For instance, anyone who sees the Kyoto Protocol as part of the global effort now required to decarbonize our economies is portrayed as dumb. Their idea that Kyoto's limits-based, target-driven process is somehow incompatible with investment in clean technology is the kind of simplistic illogicality that Tony Blair struggled with over many years' dealings with Bush.

Break Through is an important but massively flawed contribution to today's debate about the future of the environment. Its historical analysis of the movement is valuable. The promised radical alternative remains elusive - and would still be of enormous worth.

Jonathon Porritt is founder director of Forum for the Future, chairman of the UK Sustainable Development Commission and author of Capitalism as if the World Matters.

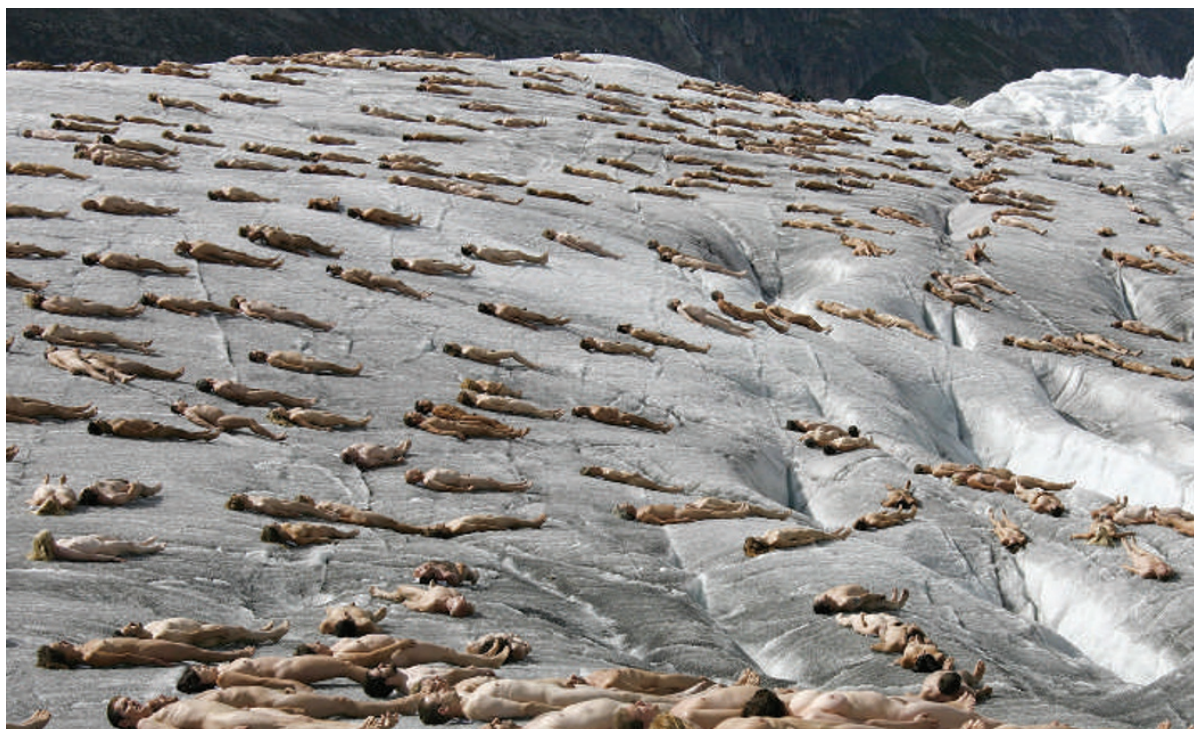

To highlight climate change, naked volunteers pose for a photo on a Swiss glacier as part of a campaign. 